\title{
Aspirin protects low density lipoprotein from oxidative modification
}

\author{
Keith A Steer, Tara M Wallace, Colin H Bolton, Martin Hartog
}

Department of Medicine, University of Bristol, Bristol K A Steer

T M Wallace C H Bolton M Hartog

Correspondence to: Dr K A Steer, Department of Diabetes and Endocrinology, Northwick Park Hospital, Watford Road, Harrow, Middlesex HA1 3UJ, United Kingdom.

Accepted for publication 10 December 1996

\begin{abstract}
Objective-To examine the effects of aspirin on the potential for oxidative modification of low density lipoprotein (LDL).

Design-Before and after trial.

Setting-University department of medicine within a district general hospital campus.

Patients-Ten healthy normolipidaemic volunteers drawn from laboratory and medical staff.
\end{abstract}

Interventions-Aspirin (enteric coated) $300 \mathrm{mg}$ daily for two weeks.

Main outcome measures-In vitro oxidation of LDL following ultraviolet C (UVC) irradiation with measurements made of malondialdehyde, conjugated dienes, and electrophoretic mobility.

Results-There was a significant decrease in malondialdehyde production from LDL modified by aspirin in vivo following exposure to UVC irradiation for $90 \mathrm{~min}-$ utes, culminating in a $30 \%$ decrease by 240 minutes (mean (SD) 64.2 (9.12) $v 89.6$ $(11 \cdot 6) \mathrm{nmol} / \mathrm{mg}$ LDL protein, $P=0.029)$. These observations were borne out using LDL modified by aspirin in vitro. The UVC induced increase in relative electrophoretic mobility of LDL was also significantly reduced following aspirin treatment (mean (SD) $2.17(0.16) v 2.66$ $(0 \cdot 24), P=0.012)$.

Conclusions-Aspirin, both in vivo and in vitro, protects LDL against subsequent oxidative modification, providing an additional mechanism whereby aspirin may protect against atherosclerosis.

(Heart 1997;77:333-337)

Keywords: aspirin; diminished LDL oxidation; low density lipoproteins

modifications in the structure of lipoproteins and in particular of low density lipoprotein (LDL). Over the past decade and a half, powerful evidence has accrued that modifications of LDL greatly increase its atherogenic potential, especially oxidative modification. ${ }^{4}$

Goldstein $e t a l^{5}$ were the first to show that modified LDL could be taken up by macrophages residing underneath the vascular endothelium, giving rise to foam cells and subsequently to the fatty streak, the earliest recognised gross lesion in atherogenesis. Chemical acetylation of LDL resulted in uptake at a rate 15 times greater than for unmodified (native) LDL. The reason for this was that such cells express few receptors for native LDL in vitro and in atherosclerotic lesions and these receptors are subject to downregulation. ${ }^{56}$ This "scavenger" receptor system also recognises other chemically modified forms of LDL, including acetoacetyl $\mathrm{LDL}^{7}$ and malondialdehyde conjugated LDL. ${ }^{8}$

Aspirin (acetylsalicylic acid) is capable of acetylating human serum proteins, both in vitro and in vivo. ${ }^{9-12}$ In addition, there is evidence to suggest that aspirin can itself generate free radicals. ${ }^{1314}$

Because of the known effects of chemical acetylation and free radical attack on LDL, both of which render it susceptible to catabolism by the macrophage scavenger receptor, we examined the effect of chemical modification of human LDL by aspirin, both in vivo and in vitro, on its potential for subsequent oxidative modification and hence its atherogenic potential.

\section{Methods}

Experiments were performed on normolipidaemic healthy volunteers from laboratory and medical staff before and after a two week treatment period with aspirin $300 \mathrm{mg}$ daily. Informed consent was obtained.

All chemicals were obtained from $\mathrm{BDH}$ and

Hypercholesterolaemia is well established as an important cause of coronary artery disease and the benefit of reducing blood cholesterol in both primary and secondary prevention of coronary artery disease is well established. ${ }^{12}$ Hypercholesterolaemia per se is not the only causative factor, however, as at any blood cholesterol concentration there is considerable variation in the clinical expression of the disease. $^{3}$

One basis for such variation rests with the complex nature of the biological response of arterial wall cells to the various postsecretory 
Figure 1 Effect of aspirin in vivo on $L D L$ oxidation. Empty circles, before aspirin; filled circles, after aspirin. Values shown are the mean of 10

experiments, error bars $=$ SEM. Significance of difference between before and after aspirin values: $\star P<0.05 ;+P<0.01$ $M D A$, malondialdehyde.

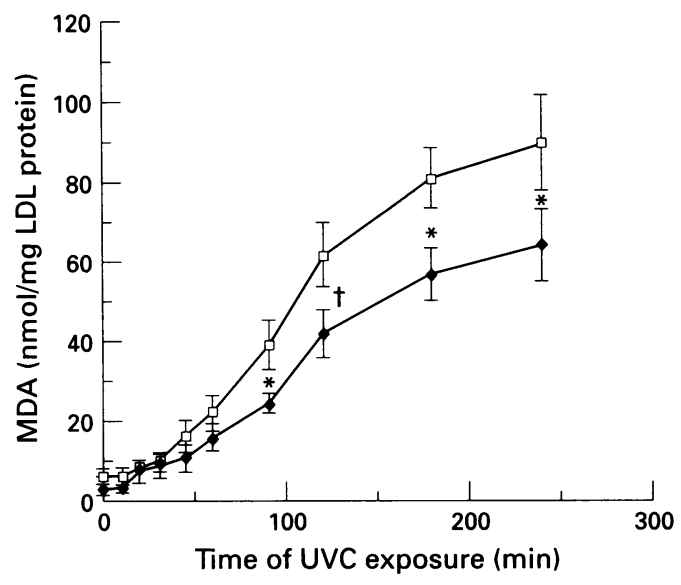

under nitrogen and used within one or two days.

LDL modified by aspirin in vitro was prepared by a modification of the method of Basu et al..$^{16} \mathrm{LDL}$ was incubated at $37^{\circ} \mathrm{C}$ for 24 hours with acetylsalicylic acid to final concentration $1 \mathrm{mM}$.

OXIDATION OF LDL

LDL was oxidised using ultraviolet C (UVC) irradiation. In vitro oxidation induced by copper ion was not used in this series of experiments in view of the known effects of aspirin on copper chelation and subsequent chelate induced lipid peroxidation. ${ }^{141718}$ LDL was divided into $100 \mu \mathrm{l}$ aliquots in silica glass tubes $(40 \times 10 \mathrm{~mm}$ internal diameter) according to the number of samples to be irradiated. Irradiation was carried out using a standard ultraviolet lamp (G8T5, $254 \mathrm{~nm}, 8 \mathrm{~W}$ ) in a Camag lamp holder, such that the silica tubes were positioned directly under the lamp, parallel to the light source. The LDL samples were therefore at a fixed distance of $10 \mathrm{~cm}$ from the source where the power level was $0.9 \mathrm{~mW} / \mathrm{cm}^{2}$ as measured by an ultraviolet meter (Blak-Ray, UVP, California, USA). The tubes containing irradiated LDL were removed from the rack at specified time intervals $(0,10,20,30,45,60,90,120,180$, and 240 minutes). Samples were stored at $4^{\circ} \mathrm{C}$ before analysis (usually the same day).

MEASUREMENT OF LDL OXIDATION

Malondialdehyde

Malondialdehyde was assayed by high performance liquid chromatography (HPLC) analysis following complexing to thiobarbituric acid according to the method of Young and Trimble. ${ }^{19}$

\section{Conjugated dienes}

Samples were examined for the development of conjugated dienes by following the increase in absorption at $234 \mathrm{~nm}$. This was done in $1 \mathrm{~cm}$ silica cells and absorption was measured in a Phillips PU8600 UV-VIS spectrophotometer.

\section{LDL electrophoresis}

This was performed on Sebia Hydragel Lipo + Lp(a) gels, using a Sebia power supply and chamber. Electrophoresis was carried out at a constant voltage of $50 \mathrm{mV}$ for 90 minutes and the gels were stained using Sudan black according to the supplier's instructions.

The contents of LDL vitamins A, E ( $\alpha$ tocopherol), and $\beta$ carotene were determined by HPLC analysis according to the method of Arnaud et al. ${ }^{20}$ Extraction and analysis of LDL fatty acids by HPLC was based on the method of Iverson et al. ${ }^{21}$

\section{STATISTICAL ANALYSIS}

Descriptive statistics were arithmetic means (standard deviation) and statistical analysis was based upon comparisons of variables made before and after aspirin treatment using paired $t$ tests. Values are given as mean (SD).

\section{Results}

Ten subjects were studied (five male, five female; age 29.5 (1.93) years). Lipid profiles were unchanged following aspirin treatment (before aspirin treatment: serum cholesterol $4.87 \mathrm{mmol} / 1$, triglyceride $1.11 \mathrm{mmol} / 1$, and high density lipoprotein (HDL) cholesterol $1.75 \mathrm{mmol} / \mathrm{l}$ ). Serum urea, creatinine, electrolytes, and albumin were within normal adult age matched reference ranges and were unchanged following aspirin treatment.

\section{EFFECT OF ASPIRIN IN VIVO ON LDL}

Formation of malondialdehyde following UVC irradiation

Malondialdehyde concentrations changed with time in a triphasic manner. After an initial period of approximately 30 minutes with little malondialdehyde production (lag phase), the concentration then rose for approximately three hours (propagation phase), after which it levelled off (decomposition phase). Basal malondialdehyde concentrations were $48 \%$ less after aspirin treatment (3.48 (1.5) v 6.64 $(1.94) \mathrm{nmol} / \mathrm{mg}$ LDL protein) thoughbecause of the wide range-this did not reach statistical significance. The lag phase was not affected by aspirin treatment. The rate of malondialdehyde production during the propagation phase was substantially reduced by treatment with aspirin. By 240 minutes 30\% less malondialdehyde $(64.2 \quad(9.12) \quad v \quad 89.6$ $(11.6) \mathrm{nmol} / \mathrm{mg}$ LDL protein, $\mathrm{P}=0.029)$ was formed from the aspirin modified LDL compared with control (fig 1).

\section{Electrophoretic mobility of $L D L$}

There was no significant change in electrophoretic mobility of LDL following aspirin treatment. A highly significant increase in electrophoretic mobility following UVC irradiation (for four hours) was observed both before and after aspirin treatment. Importantly, the increase in relative electrophoretic mobility (migration distance of oxidised to native LDL) of LDL following UVC irradiation was significantly reduced following aspirin treatment (mean (SD) after aspirin, $2 \cdot 17(0 \cdot 16) v$ before aspirin, $2.66(0.24), P=0.012$ (fig 2)) and this is in keeping with the observation that significantly less malondialdehyde was detected 
Figure 2 Effect of aspirin in vivo on relative electrophoretic mobility of LDL following UVC oxidation. Mean of 10 values, error bars $=$ SEM. Difference between before and after treatments $P=0.012$

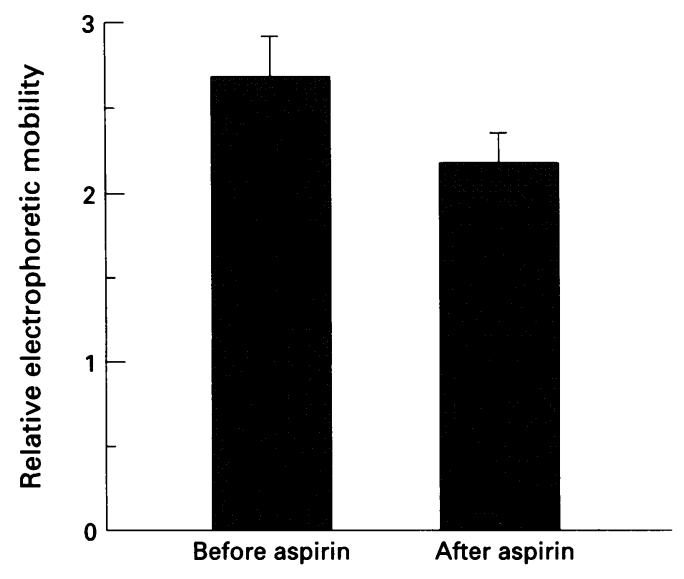

at this time. The net negative charge on the LDL molecule, and hence its mobility, would have therefore been correspondingly reduced.

\section{LDL antioxidants}

Vitamin $\mathrm{A}$ and $\beta$ carotene were below detectable limits. Vitamin E concentrations were not changed significantly by aspirin treatment (mean (SD) before aspirin 12.4 (12) $v$ after aspirin, $17 \cdot 8(17 \cdot 2) \mathrm{nmol} / \mathrm{mg}$ LDL protein).

\section{LDL fatty acids and conjugated dienes}

Conjugated dienes were not affected by aspirin treatment (mean (SD) before aspirin, 0.028 $(0.012) v$ after aspirin, $0.030(0.012) \mathrm{nmol} / \mathrm{mg}$ LDL protein) and similarly there was no effect on pentaenoic, linolenic, hexaenoic, arachidonic, or linoleic fatty acid content. There was a significant increase in oleic acid content following aspirin treatment (mean (SD) before aspirin, $2.76(1.85) v$ after aspirin, $4.85(3.12)$ nmol per mg LDL protein, $\mathrm{P}=0.024)$.

\section{EFFECT OF ASPIRIN IN VITRO ON LDI}

Formation of malondialdehyde following UVC oxidation

A comparison was made of the malondialdehyde concentrations generated by UVC irradiation for four and eight hours using LDL modified in vitro by aspirin. Basal malondialdehyde concentrations and those at four and eight hours of UVC exposure were all significantly reduced in the aspirin modified LDL (fig 3). We have previously observed a fall in malondialdehyde concentrations following

Figure 3 Effect of aspirin
in vitro on
malondialdehyde $(M D A)$
production before and after
four and eight hours of
UVC oxidation. Mean of
10 observations, error bars
$=S E M$. Differences
between aspirin modified
(grey bars) and
unmodified (black bars)
LDL achieved the
following levels of
significance: ${ }^{\star} P<0.05 ;$
$\dagger P<0.001 ; \ddagger P<0.0001$.

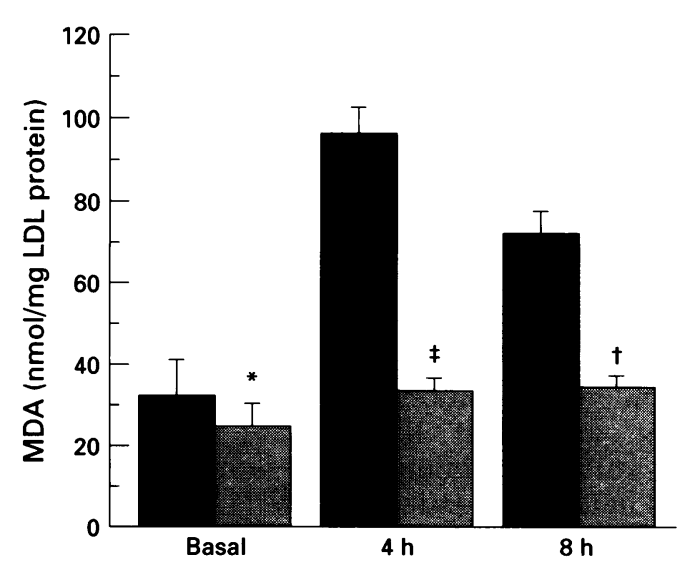

prolonged UVC exposure (unpublished observations) and this was seen here in the case of native LDL. The aspirin modified LDL did not, however, show this phenomenon and malondialdehyde concentrations were slightly higher at eight than at four hours.

\section{Discussion}

This study provides evidence that LDL modified by aspirin, both in vitro and in vivo, is protected against subsequent oxidative modification.

Oxidatively modified LDL can affect the atherosclerotic process in various ways. It can directly injure endothelial cells. ${ }^{22}$ Furthermore, oxidised LDL can attract circulating monocytes into the subendothelial space and inhibit their subsequent mobility. ${ }^{23} 24$ One of the most interesting facets is its capacity for rapid uptake into tissue macrophages which subsequently form foam cells.

Most of the cholesterol entering the macrophage is derived from serum lipoproteins, especially LDL. The macrophage, however, expresses few receptors for native (unmodified) LDL, and hence uptake is slow. In direct contrast, chemically modified LDL (acetylated, acetoacetylated, or malondialdehyde conjugated) is taken up rapidly by an alternative receptor, the so called scavenger receptor. ${ }^{578}$

The apoprotein B epitopes which bind to the scavenger receptor are formed almost exclusively during the period when lipid hydroperoxides decompose to secondary oxidative products. ${ }^{25}$ In the case of LDL oxidised in vitro, this corresponds to the decomposition phase which follows oxidation, ${ }^{26}$ seen as a flattening off of the curve in fig 1 .

Oxidation of aspirin modified LDL by ultraviolet $\mathrm{C}$ irradiation was retarded to a highly significant degree in these experiments. The malondialdehyde concentrations at the start of the decomposition phase (four hours of UVC irradiation) were $30 \%$ less in the LDL modified by aspirin in vivo ( 64.2 versus 89.6 $\mathrm{nmol} / \mathrm{mg} \mathrm{LDL}$ protein) and $65 \%$ less at the same time in the LDL modified by aspirin in vitro ( 33.4 versus $95.2 \mathrm{nmol} / \mathrm{mg} \mathrm{LDL}$ protein). Thus the inherent capacity of LDL to undergo oxidative modification to a degree which renders it susceptible to uptake by the scavenger receptor is markedly reduced by aspirin, both in vivo and in vitro. Basal levels of malondialdehyde were also reduced by both in vitro and in vivo aspirin modification $(24 \%$ and $48 \%$, respectively), though this was only significant in the in vitro modified group. This suggests that aspirin is also able to reduce the inherent capacity of LDL to undergo oxidation.

As LDL becomes oxidised it undergoes a series of changes both in its physical and chemical properties. The malondialdehyde produced results in an increase in the net negative charge on the LDL molecule and renders it more mobile in an electrical field. The mechanism may involve both the binding of aldehyde to the free amino groups of lysine, 
thus reducing the net positive charge, and free radical conversion of positively charged histidine and proline to the negatively charged aspartate and glutamate. ${ }^{25}$

Jurgens $e t a^{26}$ showed a close linear relation between the relative electrophoretic mobility of modified LDL and its uptake into macrophages through the scavenger receptor. The scavenger receptor only recognises a certain pattern of negative charge on the apoprotein B molecule, with the density of charge at defined regions of the apoprotein $B$ molecule being important. The relative electrophoretic mobility (REM) of the LDL following oxidation was significantly reduced by in vivo modification with aspirin (2.17 $v 2.66)$, in keeping with the observation that significantly less malondialdehyde was produced $(64.2 v 89.6$ $\mathrm{nmol} / \mathrm{mg}$ LDL protein).

The mechanism whereby aspirin affords LDL protection against oxidative modification is unclear, though there are several possible explanations.

Grootveld and Halliwell used aspirin to detect hydroxyl radical formation in vivo. ${ }^{27}$ They showed that aspirin undergoes aromatic hydroxylation when exposed to hydroxyl radicals to form a specific set of hydroxylated products. With this in mind, it is possible that hydroxyl radicals formed when LDL undergoes oxidative modification, in this case following exposure to UVC irradiation, react with the aromatic nucleus of the salicylate molecule and are therefore neutralised.

Lysine residues in the LDL apoprotein B molecule are modified by malondialdehyde, rendering it susceptible to further oxidative modification and uptake by the scavenger system. ${ }^{28}$ Aspirin too reacts by transferring its acetyl group to the lysine residues of human serum proteins, including LDL. ${ }^{2930}$ Malondialdehyde is also produced in human cataract as a byproduct of thromboxane synthesis. Aspirin inhibits the cross linking of human lens crystallin protein by malondialdehyde in vitro, by preventing access to the primary amino groups necessary for covalent cross linking and hence cataractogensis. ${ }^{31} \mathrm{~A}$ similar action may operate with respect to LDL oxidation. The fall in malondialdehyde concentration which occurs during the later stage of UVC oxidation of native LDL may be caused by the malondialdehyde complex being converted from the reversible Schiff base to an irreversible Amadori product, which is inaccessible to the TBA reaction. It is possible that aspirin prevents this process as described above. Thus - as was shown in these experiments-in aspirin modified LDL the concentration of malondialdehyde did not fall during the later stages of oxidation.

Aspirin could also be exerting an effect by inhibiting the prostaglandin generating system. Free radicals are generated through the prostaglandin synthase reaction and these are capable of initiating lipid peroxidation. ${ }^{32}$ Aspirin has been shown to inhibit this sequence in experimental studies examining free radical production and lipid peroxidation, including rat heart. ${ }^{33}$ Against this would be the observation that aspirin exerted an inhibitory effect on lipid peroxidation not only in vivo but also in vitro. Similarly, an increase in the LDL content of the monounsaturated fatty acid, oleic acid, which almost doubled following aspirin treatment in vivo, would reduce the oxidisability of $\mathrm{LDL}^{34}$ but again this would not account for the effect seen on LDL modified in vitro.

The in vivo and in vitro effects of aspirin on LDL oxidation seem to confer important benefit with regards to reducing its oxidisability, and hence its atherogenicity. However, modification of LDL by aspirin would at first sight be expected to render it more susceptible to macrophage uptake by virtue of its increased net negative charge and electrophoretic mobility. ${ }^{26}$ Maziere et al did, however, show that such modified LDL is a poor candidate for uptake by the scavenger receptor, despite the electrochemical changes induced by aspirin derivatisation. ${ }^{29}$

In conclusion, aspirin modifies LDL, both in vivo and in vitro, to a form which resists both endogenous and UVC induced oxidation, and this is likely to result in a significant reduction in the atherogenic potential of LDL. This study provides evidence of a hitherto unrecognised mechanism whereby aspirin offers protection against vascular disease and raises the question as to whether aspirin should play a routine part in the management of patients with dyslipidaemia.

We acknowledge the generous financial support of the Southmead Hospital Research Foundation and the expert technical assistance of Mrs Maggie Hopton and Miss Julia Ford. Helpful comments on the manuscript by Dr Jeremy Dwight are gratefully acknowledged.

1 Shepherd J, Cobbe SM, Ford I, Isles CG, Lorimer AR, MacFarlane PW, et al. Prevention of coronary heart disease with pravastatin in men with hypercholesterolemia. N Engl F Med 1995;333:1301-7.

2 Lewis B. Lipid lowering in the secondary prevention of ischaemic heart disease. In: Laker MF, Neil A, Wood C, eds. Cholesterol lowering trials. London: Royal College of eds. Cholesterol lowerning thicians, 1993:45-57.

3 Piper J, Orrild L. Essential familial hypercholesterolemia and xanthomatosis: follow-up study of twelve Danish and xanthomatosis: follow-up study

4 Steinberg D, Parthasarthy S, Carew TE, Khoo JC, Witzum $\mathrm{JL}$. Beyond cholesterol: modifications of low density lipoprotein that increase its atherogenicity. $N$ Engl f Med 1989;320:915-24.

5 Goldstein JL, Ho YK, Bass SK, Brown MS. Binding site on macrophage that mediates uptake and degradation of acetylated low density lipoprotein producing massive cholesterol deposition. Proc Natl Acad Sci USA 1979;76. 333-7.

6 Brown MS, Goldstein JL. Lipoprotein metabolism in the macrophage: implications for cholesterol deposition in atherosclerosis. Annu Rev Biochem 1983;52:223-61.

7 Mahley RW, Innerarity TL, Weisgraber KH, Oh SY. Altered metabolism (in vivo and in vitro) of plasma lipoproteins after selective chemical modification of lysine residues of the apoproteins. F Clin Invest 1979; 64:743-50.

8 Fogelman AM, Schechler I, Seager J, Hokom M, Child JS Edwards PA. Malondialdehyde alteration of LDL leads to cholesteryl ester accumulation in human monocyteto cholesteryl ester accumulation in human monocyte-

9 Pinckard RN, Hawkins FR, Farr RS. In vitro acetylation of plasma proteins, enzymes and DNA by aspirin. Nature plasma proteins,

10 Hawkins D, Pinckard RN, Farr RS. Acetylation of human serum albumin by acetylsalicylic acid. Science 1968;160: $780-1$.

11 Hawkins D, Pinckard RN, Crawford IP, Farr RS Structural changes induced by ingestion of acetylsalicylic acid. $\mathcal{F}$ Clin Invest 1969;48:536-42

12 De Fura FG, Cerami A, Bunn HF, Lu YS, Peterson CM The effect of aspirin on sickling and oxygen affinity of erythrocytes. Proc Natl Acad Sci USA 1973;70:3707-10.

13 Pihan G, Regillo C, Szabo S. Free radicals and lipid peroxidation in ethanol or aspirin-induced gastric mucosa injury. Dig Dis Sci 1987;32:1395-402. 
14 Kirkova M, Ivancheva E, Russanov E. In vitro effects of aspirin on malondialdehyde formation and on activity of antioxidant and some metal-containing enzymes. Comp Biochem Physiol Pharmacol Toxicol Endocrinol 1994;108. Biochem

15 Kleinfeld HA, Hak-Lemmes HLM, Stalinhoef AFH, Demacker PNM. Improved measurement of low density lipoprotein susceptibility to copper-induced oxidation:
application of a short procedure for isolating low density application of a short procedure for isolating

16 Basu SK, Goldstein JL, Anderson RGW, Brown MS. Degradation of cationised low density lipoprotein and regulation of cholesterol metabolism in homozygous familial hypercholesterolaemia fibroblasts. Proc Natl Acad Sci USA 1976;73:3178-82.

17 Schwartz KB, Arey BJ, Tolmonk K, Mahanty S. Iron chelation as a possible mechanism for aspirin-induced malondialdehyde production by mouse liver microsomes and mitochondria. $\mathcal{F}$ Clin Invest $1988 ; 81: 165-70$.

$18 \mathrm{McGraham} \mathrm{MC}$. Copper and aspirin treatment increase the antioxidant activity of plasma. Agents Actions 1990; 31:39-64

19 Young IS, Trimble ER. Measurement of malondialdehyde in plasma by high performance liquid chromatography with fluorometric detection. Ann Clin Biochem 1991;28: 504-8.

20 Arnaud J, Fortis I, Blachier S, Kia D, Favier A. HPLC analysis of vitamins $\mathrm{A}$ and beta-carotene in plasma and analysis of vitamins $A$ and beta-carotene in plasma and LDL. F Chromatogr 1991;572:103-16.

TL. A method for the measurement of a diene-conjugated derivative of linoleic acid, 18:2 $(9,11)$ in serum phospholipid, and possible origins. Ann Clin Biochem 1985;22:137-40.

22 Hessler JR, Robertson AL, Chisholm GM. LDL-induced cytotoxicity and its inhibition by HDL in human vascular smooth muscle and endothelial cells in culture. Atherosclerosis 1979;32:213-21.

23 Quinn MT, Parthasarathy S, Steinberg D. Endothelial cellderived chemotactic activity for mouse peritoneal macrophages and the effects of modified forms of low density lipoprotein. Proc Natl Acad Sci USA 1985;82: 5949-53.
24 Quinn MT, Parthasarathy S, Fong LG, Steinberg D. Oxidatively modified low density lipoproteins: a potential role in recruitment and retention of monocyte/ macrophages during atherogenesis. Proc Natl Acad Sci USA 1987;84:2995-8.

25 Esterbauer H, Dieber-Rotheneder M, Waeg G, Striegl G Jurgens G. Biochemical, structural and functional properties of oxidised low-density lipoprotein. Chem Res col 1990;3:77-92.

26 Jurgens G, Hoff HF, Chisholm GM and Esterbauer H. Modification of human serum low-density lipoprotein by oxidation-characterization and pathophysiological implications. Chem Phys Lipids 1987;45:315-36.

27 Grootveld M, Halliwell B. Aromatic hydroxylation as a potential measure of hydroxyl-radical formation in vivo Biochem $\mathcal{F} 1986 ; 237: 499-504$.

28 Henrikson T, Mahoney EM, Steinberg D. Enhanced macrophage degradation of LDL previously incubated with cultured endothelial cells: recognition by receptors for acetylated LDL. Proc Natl Acad Sci USA 1981;78: 6499-503.

29 Maziere C, Goldstein S, Moreau M, Maziere JC, Polanarski J. Aspirin induces alterations in low-density lipoprotein and decreases its catabolism by cultured human fibroblasts. FEBS Lett 1987;218:243-6.

30 Shamsuddin M, Mason RG, Ritchey JM, Honig GR, Klutz JM. Sites of acetylation of sickle cell haemoglobin by aspirin. Proc Natl Acad Sci USA 1971;71:4693-7.

31 Riley ML, Harding JJ. The reaction of malondialdehyde with lens protein and the protective effect of aspirin with lens protein and the protective effec

32 Kukreja RC, Kontas HA, Hess ML, Ellis ES. PGH synthase and lipoxygenase generates superoxide in the presence of NADH or NADPH. Circ Res 1986;59:612-19.

33 Manjula TS, Devi CS. Effect of aspirin on mitochondrial lipids in experimental myocardial infarction in rats. Biochem Mol Biol Int 1993;29:921-8.

34 Parthasarathy S, Khoo JC, Miller E, Barnett J, Witzum JL Steinberg D. Low density lipoprotein rich in oleic acid is protected against oxidative modification; implications for dietary prevention of atherosclerosis. Proc Nat Acad Sci USA 1990;87:3894-8. 